\title{
AUTOMATIC PROCESSING OF NATURAL FIBRES FOR INDUSTRIAL MANUFACTURING OF FIBRE REINFORCED EARTH PLASTERS
}

\author{
Jari Rintamäki and Erno Keskinen \\ Tampere University of Technology \\ P.O.Box 589, 33101 Tampere \\ Finland \\ jari.rintamaki@tut.fi \\ erno.keskinen@tut.fi
}

\author{
Tarmo Tamm \\ Clay Processing Services OÜ \\ Näituse 22-21, 50407, Tartu \\ Estonia \\ tarmo@safran.ee
}

\author{
Tönu Mauring \\ University of Tartu \\ Nooruse 1, 50411Tartu \\ Estonia \\ tonu.mauring.001@ut.ee
}

\begin{abstract}
A European research activity under title Innovative production of high quality indoor earth plaster by adding natural fibre is realizing new industrial processes for manufacturing traditional building materials. Earth plaster reinforced by natural fibres is a healthy alternative to the use of cement, lime or gypsum based plasters still producing almost the same treatment and strength properties. In comparison to the common earth plasters additives like straw, hemp or lax, natural fibre binds the mineral components symmetrically in all directions producing an isotropic strength property. The problem is now how to automate the fibre treatment process softly enough to keep fibre structure undamaged during different process phases. Industrial process consists of unit processes for receiving of raw material, separation of fibres, and separation of seeds and bones, volumetric weighing of fibre and finally packing of the fibres in bags, whose size is compatible with the batch size in the plaster production plant. The development process of the fibre handling line has been realized in two steps. The first one includes a set of small-scale laboratory tests of the unit processes as separated and the second one the design and build-up of a pilot plant in a scale, which represents a full production line capable of small production of fibres for earth plasters to be used in limited number of demonstration houses. The experiences of these developments will be utilized later in the design and delivery of a full-scale mass production plant for the fast growing European plaster markets.
\end{abstract}

\section{KEYWORDS}

Plaster Composites, Fibre Processing, Traditional Building Materials

\section{INTRODUCTION}

People spend some 95 percent of their time indoors, at home, the office, in schools and shopping. It is no secret anymore that buildings - especially modern housing - can and do make people sick. This phenomenon has been studied for at least 20 years. The list of potential indoor pollutants and effects of low-level electromagnetic radiation is growing longer each year. All this causes a multitude of body problems such as headaches, asthma, allergies, hormone disorders and even cancer [1]. It has been found out that natural Earth plaster can absorb pollutants and odours from the air: 
Pollutants, such as cigarette smoke, and odours in the air are tied to the moisture in the air and filtered out when absorbed by the earth. Health wise, this cleansing ability of clay is a further huge advantage of earth building. Earth plaster has also other positive properties [2]:

1) It regulates room temperature (passive solar design). The high mass of earth material is able to storage a lot of solar warm energy during the daytime, which can be used for heating during the night time.

2) It regulates air-moisture: Human generates moisture (breath, sweating) inside the house. Due the clays moisture balancing and buffering capacity, the natural clays prevent the respiratory system from drying out and prevent or reduce the danger of mould in rooms. Mould is suspected to be one of the most important sources for the growing spread of allergies in industrialized countries.

A European research activity under title Innovative production of high quality indoor earth plaster by adding natural fibre is realizing new industrial processes for manufacturing traditional building materials. Earth plaster reinforced by cane fibres is a healthy alternative to the use of cement, lime or gypsum based plasters still providing almost the same treatment and strength properties. In comparison to the common earth plasters additives like straw, hemp or lax, certain stellar type of fibres obtained from crops, blossoms and other kind of seed heads bind the soil granulates symmetrically in all directions producing an isotropic strength property.

The problem is now how to arrange the fibre treatment process softly enough to keep the stellar fibre structure undamaged. For this reason the use of a conventional cotton [4] or hemp ginning machine is closed out.

The development process of the fibre handling line has been realized in two steps. The first one includes a set of small-scale laboratory tests of the unit processes as separated and the second one the design and build-up of a pilot plant in a scale, which represents a full production line capable of small production of fibres for earth plasters to be used in limited number of demonstration houses. The experiences of these developments will be utilized later in the design and delivery of a full-scale mass production plant for the fast growing European plaster markets.

One vision is that there is a great market demand as there is a quick growing environmental consciousness and a fast growing demand for healthy and natural building materials. The production can be decentralized and situated at many locations where the proper earth is locally available. The transportation of the cane blossoms over long distances is economically of less relevance, as the material is extremely lightweight.

It is also believed that there is a great market demand and opportunity for the natural earth plaster system, as no satisfactory solution can be found nowadays for the economic production of competitive and high quality earth plasters in Europe. Employment will be created in order to build the new plaster plants, to process the cane fibres and to produce the plaster product. Furthermore, natural earth plaster supports sustainable economic development in remote areas where the needed materials (cane fibre, sand, and clay/loam) will be produced.

\section{TASK DESCRIPTION}

To get cane fibre production cost lower, defibering process technique must be developed significantly, which means new production machines with higher automation level. The problem is to develop process circuit and related machinery for the complete fibre handling process starting from harvested blossoms and ending to the feed of fibres to the mixing process to make the fibre-reinforced earth plaster.

\section{PROCESS DEVELOPEMNT}

The complete process consists of the following set of unit process (steps $2 \ldots 5$ in Fig. 1):

1. Harvesting of raw material

2. Quality and quantity control of raw material

3. Storage of raw material

4. Defibering and packing of fibres

5. Storage and transportation of fibres

6. Fibre unpacking and feeding to mixer

The quality and quantity of harvested cane blossom will be analyzed in the cane reception. Collected cane blossoms are packed to storage cases from plastic 
sacks and the quality will be checked by visual inspection. Mass of blossoms cases will be weighed and documented with more detailed data (date, supplier, harvesting place, quality).

Storage cases are located and stuck to cane blossom storage complies with "first-in firstout" principle. The moisture content and temperature of air-conditioned storage will be controlled to prevent cane blossom from mushroom growth.

After drying period blossom cases will be carried for defibering and packing unit forward one by one to defibering and packaging line.

Inside the defibering unit, the raw materials will be broken between the rotating brushes ( 3 units in line), so that blossoms fibres and stems will be separated. Separated fibres and bones will be sucked into a cyclone while the stems and part of separated seeds drops to a collection chamber to the bottom of the cyclone, because of gravity.

Collected seeds and stems can be disseminated back to natural growing area.

From cyclone upper part, separated fibres will be pneumatically transferred to the fibre feeding tower. Final plastic packs filling and dosing will be carried out with soft roll feeding system. Constant filling volume can be achieved with filling tubes. There will be separate tubes to big bags and small bags. After filling tube has a right volume of fibres, the inlet will be closed with thin board of film or carton and the fibres are compressed to a bag with vacuum and pressing equipment. Compressing is necessary to minimize storage and transportation cost. Compressed fibres are also almost hermitical conditions, which prevents mould.

After filling and closing, the bags can be weighed and production information can be added into a possible storage management system. Compressed packs will be stored in temperature and moisture controlled room, where they will be transported to earth plaster production plant.

The control room contains the process control $\mathrm{PC}$ and a user interface on the monitor screen. The user interface allows control the rotational speed and direction of variable speed electric motors. The operator has also access to monitor selected process parameters, for example the weight of volume of fibre batches. The interface for rotational speed control is implemented by special software of the motor manufacturer. The other interfaces are implemented with National Instruments LabView graphical development environment software. The data acquisition units are connected to the computer via USB ports

Compressed fibre bags will be emptied to fibre storage box (Fig. 2), which capacity has been dimensioned for 4 hour continues operation. Fibres will be uncompressed with a fluidising rotor, which will also prevent fibre arching action. From fibre storage box, fibres will be sucked in to fibre feeding tower. Fibres will be fed to the mixer with slow rotating feeding rollers. Upper feed rolls will be dosed right amount of fibre to lower feeding rolls. Fibres dosing will be based on weighing or by adjusting the volume of the lower roll chamber.

During mixer sand and loam filling lower feed rolls will be dosed fibre batch to mixer with constant speed. Fibres will be separated and blown to mixer chamber pneumatically. Fibre feeding sequence will be automated so that the operator will only fill the fibre storage box when it suites to schedule. If sand and clays moisture content is smaller that natural earth moisture content level $(6-10 \%)$, there will be difficulties to mix fibres uniformly. Mixing generates fibre clumps, which causes to plaster uneven fibre distribution. That could be harmful to end users, because strength properties of ready-made plaster could be reduced.

Problem has been solved by water jet. According detailed laboratory test fibres absorb water to fibre surface. During mixer filling sequence water-jet will be blown inside the mixer to accelerate fibre and clay mixing.

\section{DESIGN OF THE PLANT}

After specification of the technical requirements of the plant the design task was well defined. After several discussions and testing period some new machinery were developed for the unit processes. Modelling was done with AutoCAD inventor 3D design and modelling software. During design phase the feasibility of the plant design has tested with virtual 3D model by the end users. 


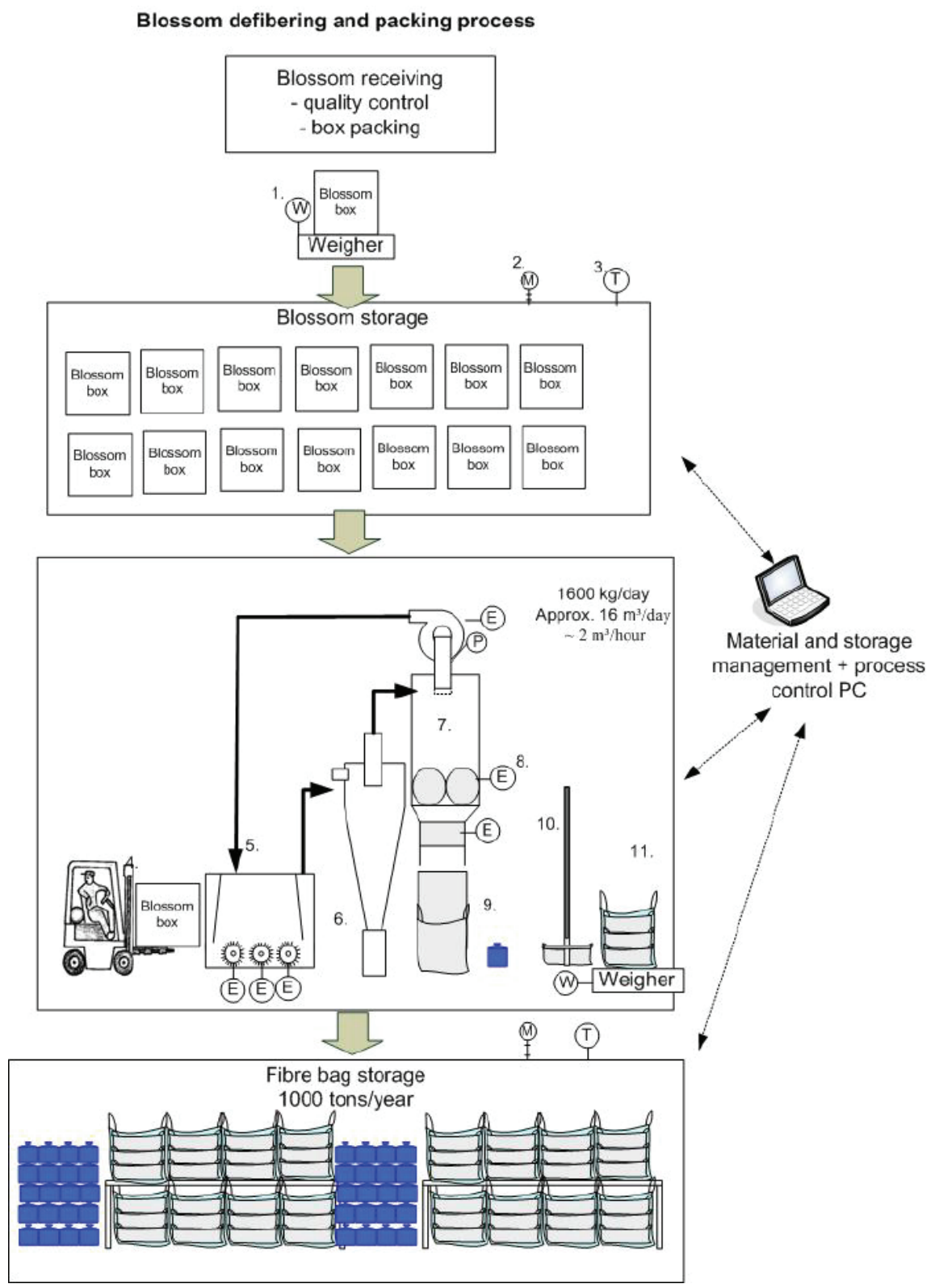

Figure 1 Fibre Production Process

Modular design has been also used to minimize machinery and spare part costs. This principle produced two machines, the defibering-packing unit and the fluidising-dosing unit, which are mainly based on the same principle and on the same design.

The defibering-packing unit (Fig. 2) for the fibre handling plant consists of the following parts for the corresponding unit processes: 
1. Defibering chamber for blossoms.

2. Cyclone for seeds and stems separation.

3. Fibre packing tower.

4. Air circulation system.

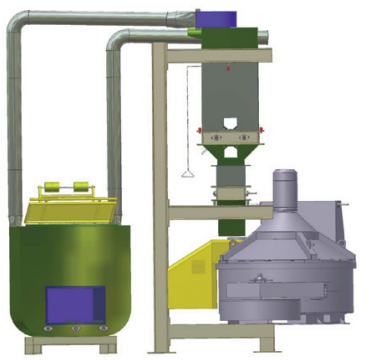

Figure 2 Fibre Defibering and Packaging Unit

PC based automation system consists of measurements and controls, which are The uncompressing-feeding unit for the plaster plant (Fig. 3) consists of the following parts:

1. Fibre bag handling system.

2. Fibre fluidising chamber.

3. Fibre feeding unit.

4. Circulation air duct and fan system.

5. Water jet unit.

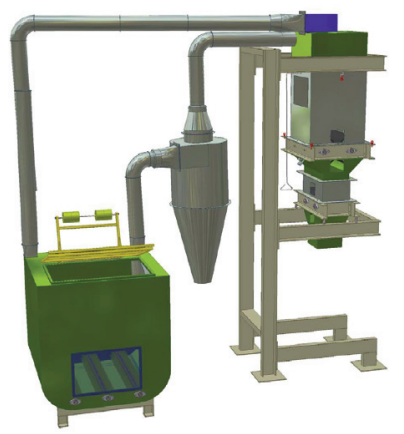

Figure 3 Fibre Fluidising and Feeding Unit

Automation system for Plaster mixing plant is much more demanding than the one for fibre handling plant. The sensing and controlling system for fibres is quite similar but additional constraint is to synchronize the fibre feeding sequence with another one controlling the dosing of soil granulates to the mixer. Materials are transported to mixer with weighing conveyors.

\section{CONCLUSIONS}

Traditional building materials like clay-based plasters are returning back. Different natural fibres obtained from blossoms of cane plants can be used to produce reinforced earth composites with better strength properties. Industrial production of such materials requires the build of a fibre separation plant and another plant for mixing the fibres with the soil granulates. These plants can stay in different locations or can be combined to one production plant. Both plants utilize a modular fibre manipulation unit, which can be used for defibering and packing purposes in the fibre handling plant or alternatively for fibre fluidising and feeding processes in the plaster mixing plant. The design has been completed by $3 \mathrm{D}$ design software AutoCad Inventor. The plant processes are automated by means of controlled weighing, dosing, feeding and conveying operations to produce constant batch size and constant quality mixing results as output of the manufacturing process.

\section{ACKNOWLEDGMENTS}

The authors wish to thank the European Commission for the financial support to co-operative research project "Plaster+ - Innovative production of earthplasters", Contract Number 031287, under which this research has been done.

\section{REFERENCES}

[1] WHO (1999), Air quality guidelines. www.who.int/environmental_information/Air/Gu idelines.

[2] Minke, G., Earth construction handbook, the building material earth in modern architecture, WIT Press , 2000, Southampton England.

[3] Biagiotti, J., Puglia, D., Kenny, J.M., A Review on Natural Fibre Based Composites- Part 1: Structure, Processing, and Properties of Vegetable Fibres. Journal of Natural Fibers Vol. 1(2), 2003.

[4] Harris, J., Machine for ginning and cleaning cotton. U.S. Patent 2,064,602, Dec. 15, 1936. 